\title{
Liliopsida anatomical traits in the Trollius species (Ranunculaceae)
}

\author{
Liubov V. Buglova*, and Anastasia S. Gusar \\ Central Siberian botanical garden SB RAS, 630090 Novosibirsk, Russia
}

\begin{abstract}
Floral shoot anatomy in Trollius asiaticus and seedling morphology in T. altaicus, T. apertus, T. asiaticus, T. europaeus, T. ledebourii and $T$ sajanensis were studied in early ontogeny stages. In four species, there occurs syncotyly, its distribution among the species of the genus being probably a valuable characteristic to understand the genus phylogeny. In T. asiaticus, vascular bundles are closed, stems are unable to any secondary increase in thicknes; sclerenchyma is not located radially but forms massive strands externally to the vascular bundles.
\end{abstract}

\section{Introduction}

Despite the fact that phylogeny issues are paid particular attention, evolutionary relationships between the flowering plant taxa are still a continuous matter of dispute limited by the lack of information. Heterobathmic taxa in which the characters of evolutionary advancement are combined with primitive ones present the particular difficulty. According to A.L. Takhtajan [1], the ancestor of the taxa with heterobathmic characters is the taxon in which both types of traits are at the primitive stage of development. So exhibiting the characters of monocots or dicots is a characteristic of basal taxa forming the foundation of the phylogenetic tree. Thus far, it can be said with certainty that no anatomic-morphological attributes strictly define one or another clade. Nonetheless, some characters are typical for the vast majority of the taxa representing one clade and relatively rare in the other clade. For example, the adventitious root system mainly occurs in Liliopsida and also, in some very few representatives of Magnoliopsida.

In Magnoliopsida clade, presence of developed endosperm as a storage tissue of seeds is a well-studied character to prove the basal position of the taxa, while this is typical for Liliopsida. As primitivism or advancement criteria such characters as structure of vessels, cambial elements, pith rays and stoma types [1].

However, phylogenic significance of some characters has not been recognized yet. They are syncotyly or adnation of cotyledons and pseudomonocotyly or false monocotyly when either cotyledon petioles form cotyledonary tubes or underdevelopment of one cotyledon is not revealed. These morphological peculiarities are being all-round studied; there are investigations on their anatomic-morphological structure and new taxa with such characters are found [2-6]. In Ranunculaceae, syncotyly occurs in Anemone blanda, A. bucharica, A. caucasica, Clematis serratifolia, Pulsatilla alba; pseudomonocoledony was established in

* Corresponding author: astro11@ rambler.ru 
Anemone genus (A. blanda, A. caucasica, A. flacsinda, A. multifida, A. ranunculoides), Thalictrum (T. sultanabadense), Eranthis, Ficaria [7, 8].

Trollius (Ranunculaceae) representatives are polycarpic grasses with fibrous root system and dicyclic semi-rosette shoots [9-11]. The adventitious root system analogous to most Liliopsida species can very often be seen in Ranunculaceae family. Apart from morphological structure, typical for monocots anatomic characters are also exhibited. For instance, in Trollius europaeus, root structure stays primitive life-long, as roots are unable to secondary increase in thickness [12]. The stem comprises angular collenchyma, vascular bundles are collateral with hardly notable cambium and lignified pith rays [12]. The author concludes that the Ranunculaceae plants with more primitive flower design have more typical for Liliopsida characters.

If characters peculiar for monocots or any other characters that prove the phyletic belonging of plants are established in Magnoliopsida, it contributes to better understanding of differentiation in the course of phylogenesis and also to revealing both development patterns and evolutionary position of the taxa.

More wide-spread in Liliopsida characters occur in Trollius representatives at different levels of their structure organisation. Microsporangium examination allowed to reveal the centripetal differentiation of the anther wall layers in $T$. ledebourii [13]. Such differentiation results from the fact that the development of microsporangium layers follows the monocotylous mode.

By studying the morphology of Trollius seedling it was found out that cotyledon petioles are adnate in $T$. asiaticus and not adnate in T. chinensis, $T$. pumilus, $T$. europaeus [14]. The author offers the degree of cotyledon adnation as a diagnostic character, although no discussion on its phyletic importance is given. Nevertheless, this character also occurs in representatives of other genera. It can determine the genus in whole, but more often being the character of an intrageneric group $[4,15,16]$. In its turn, syncotyly is not inherent in Liliopsida since the plants are monocots, but this character should be paid attention as it is rather rare and thus scarcely studied in Magnoliopsida.

It is acute to search for anatomic characters of Trollius species which ether are more spread in Liliopsida or have less phyletic significance. In that regard, we have studied the anatomy of plants at the early ontogenetic stages and of elongated shoots at their generative ages of some Trollius species.

\section{Materials and methods}

Early ontogenetic stages were studied in the following Trollius species: T. altaicus C.A. Meyer, T. apertus Perf. ex Igoschinaof section Trollius Doroz.; T. asiaticus L., T. ledebourii Reichenb. of section Longipetala Doroz.; $T$ sajanensis (Malychev) Sipl. Seedling anatomy was investigated only in T. asiaticus, T. ledebourii.

Swelled seeds and seedlings were fixed in FAA (formalin, acetic acid, ethanol), then longitudinal and transversal slices were prepared by standard technique on the freezing sliding microtome MS-2 with a thermoelectric cold plate TCP-II [17]. The material was dyed with phloroglucinol or alcian blue [18] and examined under the light microscope Carl Zeiss Axio Scope A1.

\section{Results and discussion}

The floral shoot stems in both Trollius species under the study are upright. Vascular bundles are located in one row as in most Magnoliopsida. The stem structure is similar to the one of Liliopsida plants; vascular bundles are closed with no interbundular or bundular 
cambium, thus secondary increase in stem thickness cannot take place (Fig. 1). Sclerenchyma is not located radially but forms massive strands externally to the vascular bundles. That provides it good support function, but makes the stem as break-brittle as a culm.

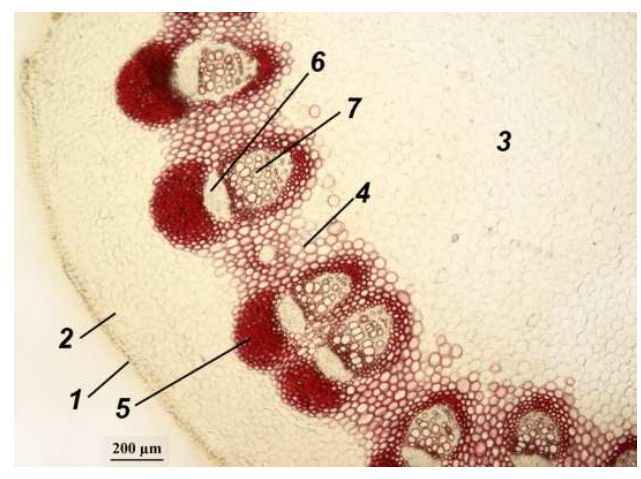

Fig. 1. Transversal slice of the Trollius asiaticus L floral shoot dyed with phloroglucinol.

1. Epidermis, 2. Chlorenchyma, 3. Medullar parenchyma, 4. Interbundular parenchyma, 5. Sclerenchyma, 6. Phloem, 7. Xylem; Bar $0.2 \mathrm{~mm}$

In the literature, vascular bundles of Trollius europaeus are described as open ones [12]. However, the author does not provide the figures of stem vascular bundles. Analysing her pictures, we failed to find the cambial layer there. It is neither observed in the vascular bundles of elongated shoots in T. asiaticus. The medullar parenchyma is loose; it early withers away and the stem turns hollow.

Adnate cotyledon petioles have been observed in $T$. asiaticus, in the hybrid species $T$. apertus, and in introgressive natural forms T. altaicus (the Seminski range, the Altai Republic, Russia) and T. sajanensis (Hamar-Daban, Irkutsk Oblast, Russia). Introgressive forms are determined by morphological criteria. Despite presented a group of diagnostic characters defining their species membership, these forms differ from the typical specimens by insignificant deviation towards $T$. asiaticus, as they have longer and more numerous petals. In T. europaeus, syncotyly was not revealed, however the seedlings of our artificial hybrid $T$. asiaticus $\times T$. europaeus exhibit syncotyly in all the specimens of the $\mathrm{F}_{2}$ generation. That makes us consider syncotyly as an inheritable character which is steadily passed by hybridisation.

In syncotylous species and forms, initial stages of germination are the same. Embryos in fully developed seeds are immature, usually, development stages from the early heart to the early torpedo ones. Position of the two symmetric cotyledon germs is normal, but the cotyledonary tube, hypocotyl and primary root are not differentiated yet.

Embryo development and its germination take place in the course of stratification. The vegetative cone of the shoot appears in the center of the embryo axial part as a group of meristematic initials. Then the layer of axial cells straight above the meristematic apical zone undergoes lysis. The cell layers located higher and aside from the apex form the cotyledonary tube. Germination (growing from the seed) begins after the part of the embryo under the epical meristem differentiates into a hypocotyl and primary root.

In Trollius, seed germination is cotyledonous. According to Barykina and Chubatova [19], this term should be used for the seeds whose seed coat is brought above the soil surface by cotyledons (in this case, by the cotyledonary tube), while the plumule stays at the ground level. Cotyledonary Trollius species have hardly expressed hypocotyl with no growth potential; its diameter is close to the diameter of the cotyledonary tube and just slightly more than the one of the root. A young shoot apex is presented by a weakly convex vegetative cone. During the further development, symmetry of the cotyledonary tube shifts 
to the side position. The slit which appears due to the lysis process over the vegetative cone is filled with leaf primordia. With their growth, the first simple leaf emerges by breaking through the epidermis of the cotyledonary tube (Fig. 2) which surrounds the vegetative cone and primordia of true leaves at the height of $1-1.5 \mathrm{~mm}$.

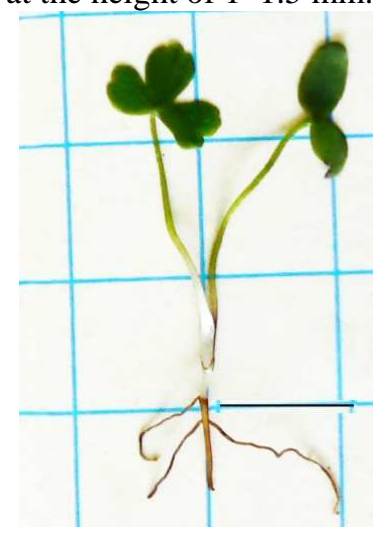

Fig. 2. Trollius altaicus seedlings (Seminski range, the Altai Republic, Russia) with a cotyledonary tube (in the right) and a first true leaf (in the center); bar $10 \mathrm{~mm}$.

The scholars, who study syncotylous plants, mention positive geotropic growth of the lower part of the cotyledonary tube. Thus the plumule is pulled to some depth into the soil and protected from negative environmental conditions. In the process, both hypocotyl and the lower part of the cotyledonary tube can perform absorption and have hairs, as for example in some representatives of Trifolium and Podofillum [4, 15]. In Trollius plants, the hypocotyl is clearly separated from the root and does not produce root hairs. Differentiation of hypocotyl sub-epidermal layers is photo-dependent. Initially, they differentiate as chlorenchymous cells, but soon lose chlorophyll and develop as parenchymous ones.

Unlike the Podofillum genus [4], in T. asiaticus seedlings, the cotyledonary tube is filled with intercalary meristem cells at the early stages and there are no root hairs in its base, while later the chlorenchyma differentiates sub-epidermically so as to give rise to axially elongated cells of parenchyma located closer to the centre. Primary vascular system emerges as common in the root and hypocotyl, discontinues at the apex area and then can be seen as two strands in the cotyledonary tube. On further development, the tear of the vascular system disappears.

Accordingly, the cotyledonary tube of $T$. asiaticus should not be considered as the expression of pseudomonocotyly, because for the entire duration of embryo development there can be clearly seen two cotyledons. As a term, "adnation of cotyledons" describes the process of cotyledonary tube forming not clearly. It initiates in the axial part of an embryo and has not any sign of division into two petioles. In Trollius, syncotyly is an inborn inherited character and we suppose the phenomenon not to be linked with hypomorphosis. The cotyledonary tube of Trollius species performs protection of the vegetative cone and bringing first assimilative organs of the seedling to the surface.

Adnate cotyledons are typical for evolutionary basal taxa as Trollius and Podophyllum, and also for rather advances as Amyema, Barathranthus, Helicanthes, Lysiana, Mocuiniella, etc. $[4,16]$. The matter of interest is the fact that in the vast majority of genera, adnate cotyledonary tubes characterize not the whole taxon but a group of genetically close species, hence this character should be analysed from the position of intra-generic differentiation. In some species of Trollius Longipetala, syncotyly is not observed. These are T. ledebourii by our data and T. chinensis by literature [14]. However, the phenomenon occurs in the other two species of the section: T. apertus and T. altaicus. This character does not correspond to the interpretation of the section subdivision by [20]. Taking into 
account the genetic stability of the character, we recommend to include it to the next sectional revision of the genus. Also, its phylogenetic significance should be evaluated.

Analysis of literature and results of our investigations makes us conclude that close to Liliopsida characters are registered in the anatomic-morphological structure of root system, anatomy of vascular bundles, presence of endosperm as a storage tissue of seeds, and differentiation of microsporangium walls. Stem vascular bundles located in one layer and syncotyly in some species should be referred to specific traits. Such a combination creates an individual cluster of characters typical for all the Trollius representatives.

The study was conducted according to the scientific project of FSFIS Central Siberian Botanical Garden SB RAS “Analysis of biodiversity, protection and restoration of rare and resource plant species by experimental methods” № AAAA-A21-121011290025-2.

\section{References}

1. A. L. Takhtajan, System and phylogeny of flowering plants (Moscow-Leningrad, Nauka, 1966)

2. B. Haccius, Planta, 41 (5) (1953)

3. I. G. Zoz, Proceedings of the USSR Acad. of Sci., 146 (4) (1962)

4. R. P. Barykina, Botanical J., 56 (7) (1971)

5. R. Y. Plennik, Anatomo-morphologic peculiariries of seeds of Fabaceae of SouthEastern Asia. Seed quality with regard to conditions of their formation at the introduction (Novosibirsk, 1971)

6. L. Y. Tomkovich, Bulletin of the Main Botanical Garden, 116 (1961)

7. R. P. Barykina, Byull. MOIP Biol. Sec., 104 (1) (1999)

8. P. Forster, Seedling morphology in the tribus Anemoneae DC. (Ranunculaceae), Flora, Vol. 194 (1999)

9. L. A. Zhukova, Population life of meadow plants (Yoshkar-Ola, Lanar, 1995)

10. S. N. Ziman, Morphology and phylogeny of Ranunculaceae, (Kiev, Naukova dumka, 1985)

11. L. V. Buglova, O. V. Komina, M. V. Kozlova, Ontomorphogenesis of T. ledebourii ex situ in the Western Siberia forest-steppe continental climate, Vestnik of Orenburg St. Pedagogical Univ., 2 (34) (2020)

12. L. A. Kuklina, Bulletin of the Main Botanical Garden, 42 (1961)

13. L. V. Buglova, Plant life of Asian Russia, 1(21) (2016)

14. N. P. Lubyagina, Botanical J., 70, № 12 (1985)

15. E. Y. Ilyina, Cotyledonary tube in cloves and its significance, Electronic scientific archive of Ural Fed. University, (1976)

16. A. L. Takhtajan, Comparative anatomy of seeds, V. 6. Dicotiledons. Rosidae (Saint Petersburg, Nauka, 2000)

17. W.A. Jensen, Botanical Histochemistry: Principles and Practice (Moscow, Mir, 1965)

18. R. P. Barykina, T. D. Veselova, A. G. Deviatov, H. H. Djalilova, G.M. Ilyna, N.V. Tschubatova, Guide of botanical microtechnics. Foundations and methods (Moscow, Mosk. St. Univ. Press, 2004)

19. R. P. Barykina, N. V. Chubatova, On types of germination and the first stages of ontogenesis in the Clematis L., Bulletin of the Main Botanical (Moscow, Nauka, 1981)

20. A. Doroszewska, Monographiae Botanicae, 41 (1974) 